\title{
Associations between Mother's BMI, Fruit and Vegetable Intake and Availability, and Child's Body Shape as Reported by Women Responding to an Annual Survey
}

\author{
Caitlin Dow ${ }^{1}$, Betsy C. Wertheim ${ }^{2}$, Elizabeth Pivonka ${ }^{3}$, Cynthia Thomson ${ }^{4}$ \\ ${ }^{1}$ Department of Nutritional Sciences, University of Arizona, Tucson, USA; ${ }^{2}$ University of Arizona Cancer Center, Tucson, USA; \\ ${ }^{3}$ Produce for Better Health Foundation, Hockessin, USA; ${ }^{4}$ Mel and Enid Zuckerman College of Public Health, University of Arizona, \\ Tucson, USA. \\ Email: cdow@email.arizona.edu
}

Received October $15^{\text {th }}, 2012$; revised November $15^{\text {th }}, 2012$; accepted November $23^{\text {rd }}, 2012$

\begin{abstract}
Previous evidence indicates that a child's body mass index (BMI) and eating behaviors are often related to the BMI and eating behaviors of his/her parents. Additionally, there is evidence suggesting that fruit and vegetable intake may impart weight control benefits. The purpose of this study was to examine the relationship between mother's BMI and the intake/availability of fruits and vegetables in the home, as well as mother's perceived body shape of her child. This is a cross sectional, descriptive analysis of results from a large internet-based survey of Generation X and Y mothers evaluating the role of fruit and vegetable consumption and health behaviors in US families. Mothers $(n=1469)$ with children under the age of 18 living in the home reported her BMI, her fruit and vegetable intake, and fruit and vegetable availability in the home. Additionally, mothers with children between the ages of 2 and $12(n=1177)$ reported her child's body shape (using graduated images of children ranging from the 3rd - 97th percentiles of BMI). Mother's BMI was not related to fruit or vegetable intake, though it was inversely related to fruit, but not vegetable, availability in the home. Mother's BMI was also positively related to child's body shape, and mother's fruit, but not vegetable, intake was inversely related to child's body shape. Our findings support a potential role for fruit availability promoting healthy BMI in mothers and/or healthier body shape in their children.
\end{abstract}

Keywords: Fruits; Vegetables; Mothers; Children; BMI

\section{Introduction}

Obesity is a health concern in adults and children [1-3], ultimately resulting in an increased risk for chronic diseases including Type 2 Diabetes, cardiovascular disease, and cancer [4,5]. Evidence suggests that children's body mass index (BMI) and eating behaviors are associated with the BMI and eating behaviors of their parents $[2,6$, 7]. Increased fruit and vegetable (FV) consumption as part of a healthy, balanced diet is an established health goal in the US [8] and is often recommended by practitioners as a targeted behavioral strategy to reduce body weight [9-11].

The social ecological theory suggests that the environment plays an important role in behavior development, and the family environment is especially important in the development of eating behaviors in children [12]. Evidence correlating FV intake in children and the role of

\footnotetext{
"The authors have no conflicts of interest to report.

Funding for the survey was provided by the Produce for Better Health Foundation.
}

parental FV consumption and attitudes has been evaluated in both systematic reviews and nationally representative surveys $[12,13]$, though a recent systematic review and meta-analysis found only a weak association [14]. A review evaluating the role of the home environment on FV intake in children and adolescents showed that availability, parental modeling, and parental intake were all positively associated with children's FV consumption [12]. The role of the mother in children's eating behaviors may be of particular importance, as mothers characteristically spend more time than fathers with children and have more influence over feeding activities [15]. There is a large body of evidence suggesting that parental intake of FV, specifically, is highly associated with children's intake [7, 13,16].

Despite the established role of parental choices and modeling on children's FV intake, there is a lack of data regarding the complex relationship between a mother's FV intake and her BMI and the relationship of these parameters to her child's FV intake and body shape (i.e. ecto- 
morph, mesomorph, or endomorph).

A large internet survey of mothers with children residing in the home conducted annually on behalf of the Produce for Better Health Foundation affords a unique opportunity to further explore these relationships. Specifically, this report sought to evaluate the relationships between FV intake/availability and BMI of mothers, maternal BMI and her child's body shape, and maternal FV intake/availability and mother's perception of her child's body shape. We anticipated that FV intake/availability would have an inverse relationship with BMI, maternal BMI would be associated with larger reported body shape of the child, and maternal FV intake/availability would be associated with smaller perceived child's body shape.

\section{Methods}

\subsection{Survey Development}

An annual online consumer survey was originally developed by the Produce for Better Health Foundation Research Board in collaboration with Ogilvy Public Relations Worldwide, the public relations agency for Fruits \& Veggies-More Matters ${ }^{\circledR}$ and OnResearch, Inc. (Ontario, Canada). A pilot study was conducted in 2006 in Generation X (GenX; individuals born between 1965-1979) mothers $(\mathrm{n}=73)$, further reviewed and refined, and sent to outside reviewers with behavioral expertise for additional review. The baseline survey was fielded in February 2007 in 1000 mothers and has been completed annually since 2007 in US mothers.

Questions were developed to obtain information about knowledge, attitudes, and beliefs of GenX mothers and to gain insight into barriers to providing fruits and vegetables to their families. The sample of potential participants was drawn from membership lists of survey panels for online companies who partner with OnResearch, Inc. Potential respondents who met inclusion criteria were invited via email to participate in the survey. Respondents included mothers born between 1965 and 1990 with at least one child under the age of 18 . Those who completed the survey were given a small cash reward for participating. Each year, the survey is completed in women who have not participated in previous years.

Most questions were answered using a 5-point Likert scale, though several questions required open-ended responses. Respondents were asked to provide information regarding their personal $\mathrm{FV}$ intake and $\mathrm{FV}$ availability in their home (including fresh, canned, frozen, or dried). The survey stated that a serving of fruit/vegetable was approximately the size of a tennis ball, and women provided a numerical response for the number of servings they ate each day. Women reported their average daily intake of fruits and vegetables separately.

\subsection{Additional Survey Sections Added in 2011 Survey}

In 2011, additional survey questions were developed that had not been used in previous surveys. All data for the current analysis were collected January 14-31, 2011. Mother's BMI was calculated using information from those respondents who elected to provide data on their height and weight $(92.9 \%, \mathrm{n}=1486)$. Those who reported a BMI $<15 \mathrm{~kg} / \mathrm{m}^{2}(\mathrm{n}=9)$ or $>60 \mathrm{~kg} / \mathrm{m}^{2}(\mathrm{n}=8)$ were excluded from the analytical dataset. Thus, data from 1469 mothers were included in our analyses.

Additionally in 2011, respondents were asked to report on their child's body shape only if they had children between the ages of 2 and 12 years living in the home. If a woman reported having more than one child between 2 and 12 years of age, they were asked to report on the body shape of only one child chosen at random by the survey software $(\mathrm{n}=1177)$. The images used to inform on child's body shape were produced by Truby and Paxton in 2002 [17]. The children depicted in these images ranged in size based on the 1979 National Center for Health Statistics (NCHS) BMI percentiles $(\mathrm{A}=3 \mathrm{rd}, \mathrm{B}=$ 10th, $\mathrm{C}=25$ th, $\mathrm{D}=50$ th, $\mathrm{E}=75$ th, $\mathrm{F}=90$ th, and $\mathrm{G}=$ 97th) (Figure 1). In order to assess outcomes associated with children's body size, the eight categories were collapsed into clinically relevant BMI groups: $\leq 25$ th percentile (groups A, B, and C combined), 50th percentile (group D), 75th percentile (group E), and $\geq 90$ th percentile (groups $\mathrm{F}$ and $\mathrm{G}$ combined).

\subsection{Statistical Analysis}

Associations between mother's BMI and fruit or vegetable intake were tested using linear regression. Wilcoxon's rank sum test was used to test the difference in FV intake between women who opted to provide height and weight compared to those who did not. The relationship between FV intake and FV availability in the home was tested using multinomial logistic regression and assessed for confounding by mother's BMI, though no confounding was observed. Linear regression models were also used to evaluate the differences in BMI between women who selected specific categories of FV availability among the variety of responses available. Associations were assessed for potential confounding by education, employment, marital status, age, number of children, daily physiccal activity, fruit or vegetable intake, and ethnicity. Covariates that resulted in a beta coefficient change of more than $10 \%$ were included in the final adjusted model. The covariates included in the model for 


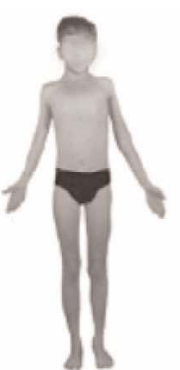

(a)

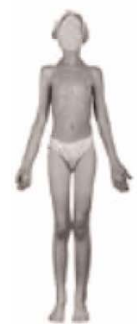

(a)

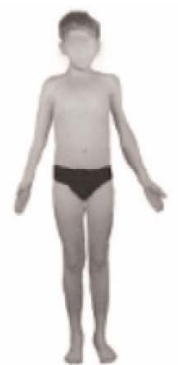

(b)

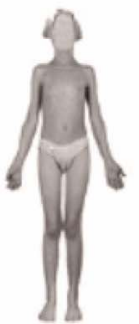

(b)

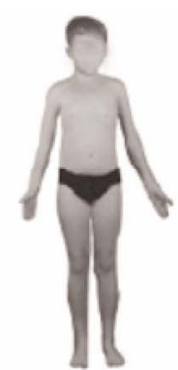

(c)

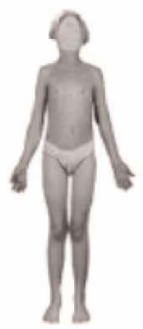

(c)

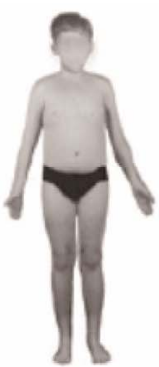

(d)

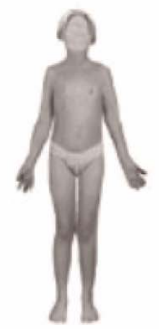

(d)

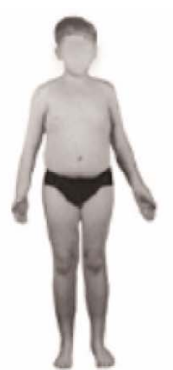

(e)

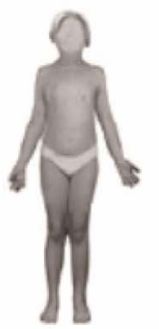

(e)

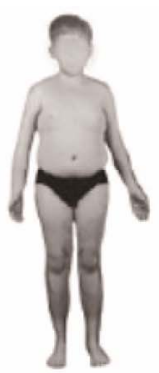

(f)

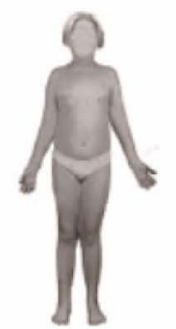

(f)

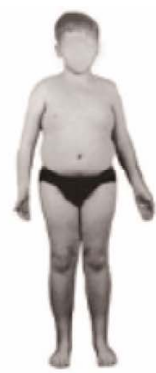

(g)

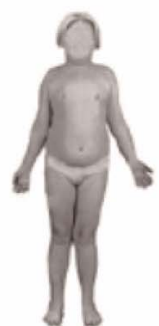

(g)

Figure 1. Child's body shape images shown to mothers responding to an annual survey regarding fruits and vegetables. Images produced by Truby and Paxton et al.

fruit availability and BMI were physical activity and education, whereas the model for vegetable availability and BMI included physical activity, education, marital status, and ethnicity.

Differences in BMI between mothers who selected various body shapes for their children were tested using ordinal logistic regression. The association between child's body shape and FV availability in the home was tested using chi-square tests. Lastly, the relationship between mother's FV intake and child's body shape was tested using ordinal logistic regression. Trends were tested by including child's body shape category as an ordinal variable in the model, wherein categories $\mathrm{A} / \mathrm{B} / \mathrm{C}=1, \mathrm{D}=2$, $\mathrm{E}=3$, and $\mathrm{F} / \mathrm{G}=4$. This trend was assessed for potential confounding by mother's BMI; no confounding was observed. All tests were considered statistically significant at $p<0.05$. Statistical analyses were performed using Stata 11.1 (StataCorp, College Station, TX).

\section{Results}

Survey respondents had a mean \pm SD age of $36.4 \pm 6.1$ years and $2.0 \pm 1.0$ children under age 18 living in the home. The mean BMI (calculated from self-reported height and weight) of mothers was $27.5 \pm 7.3 \mathrm{~kg} / \mathrm{m}^{2}$, and $54.2 \%$ of women were considered overweight or obese (BMI $\geq 25 \mathrm{~kg} / \mathrm{m}^{2}$ ). Mothers reported a mean number of daily servings of fruits of $2.6 \pm 3.0$ and a median of 2 servings. The mean number of daily servings of vegetables was $2.5 \pm 2.0$ servings, and the median intake was 2 servings (Table 1). There was no difference in fruit or vegetable intake between women who elected to provide height/weight compared to those who did not $(P=0.599$ and $P=0.680$, respectively).

\subsection{Associations between Mothers' BMI, FV Intake, and FV Availability}

No significant association was found between mother's BMI and self-reported daily servings of fruit or vegetable intake ( $P=0.125$ and $P=0.099$, respectively). However, women who reported greater availability of FV in their home did report significantly greater daily intake than those who reported lower availability (Table 2).

BMI of respondents was compared across FV availability categories. Women who reported that fruit was "always available" had a significantly lower BMI than those who reported that fruit was "almost always/ usually available" $\left(26.6 \pm 6.6\right.$ versus $28.1 \pm 7.9 \mathrm{~kg} / \mathrm{m}^{2}$, respectively; $P<0.001)$ or "occasionally/rarely/never available" $\left(26.6 \pm 6.6\right.$ versus $\left.29.4 \pm 7.1 \mathrm{~kg} / \mathrm{m}^{2} ; P<0.001\right)$ in the home (Table 3). This relationship held when adjusted for education and physical activity. Furthermore, the BMI of women who selected that vegetables were "always available" was significantly lower than those who selected that vegetables were "almost always/usually available" (26.9 \pm 6.8 versus $28.1 \pm 7.8$, respectively; $P=$ 0.001 ); women who selected that vegetables were "occasionally/rarely/never available" also demonstrated a higher BMI compared to the "always available group," 
Table 1. Characteristics of mothers responding to an annual survey regarding fruits and vegetables in $2011(\mathrm{n}=1469)$.

\begin{tabular}{|c|c|}
\hline & $\mathrm{n}(\%)$ or mean $\pm \mathrm{SD}$ \\
\hline Age (years) & $36.4 \pm 6.1$ \\
\hline Number of children per mother & $2.0 \pm 1.0$ \\
\hline Number of girls per mother & $1.0 \pm 0.9$ \\
\hline Number of boys per mother & $1.0 \pm 0.9$ \\
\hline Average age of children (years) & $7.6 \pm 4.6$ \\
\hline \multicolumn{2}{|l|}{ Ethnicity } \\
\hline White/Caucasian & $1171(79.7)$ \\
\hline Black/African American & $107(7.3)$ \\
\hline Hispanic/Latino & $97(6.6)$ \\
\hline Asian/Pacific Islander & $75(5.1)$ \\
\hline Other & $19(1.3)$ \\
\hline \multicolumn{2}{|l|}{ Annual household income } \\
\hline$<\$ 25,000$ & $274(18.7)$ \\
\hline$\$ 25,000-\$ 49,999$ & $400(27.2)$ \\
\hline$\$ 50,000-\$ 74,999$ & $348(23.7)$ \\
\hline$\$ 75,000-\$ 99,999$ & $235(16.0)$ \\
\hline$\$ 100,000-\$ 149,999$ & $161(11.0)$ \\
\hline$>\$ 150,000$ & $51(3.5)$ \\
\hline \multicolumn{2}{|l|}{ Marital status } \\
\hline Married/living with someone & $1178(80.2)$ \\
\hline Single & $150(10.2)$ \\
\hline Separated/divorced & $133(9.1)$ \\
\hline Widowed & $8(0.5)$ \\
\hline \multicolumn{2}{|l|}{ Aerobic physical activity (min/day) } \\
\hline$<30$ & $814(55.4)$ \\
\hline $30-60$ & $590(40.2)$ \\
\hline$>60$ & $65(4.4)$ \\
\hline Body mass index $\left(\mathrm{kg} / \mathrm{m}^{2}\right)$ & $27.5 \pm 7.3$ \\
\hline Underweight $(<18.49)$ & $49(3.3)$ \\
\hline Normal weight $(18.5-24.9)$ & $625(42.6)$ \\
\hline Overweight $(25.0-29.9)$ & $368(25.1)$ \\
\hline Obese $(>30.0)$ & $427(29.1)$ \\
\hline Fruit intake (servings/day) & $2.6 \pm 3.0[2.0]^{\mathrm{a}}$ \\
\hline Vegetable intake (servings/day) & $2.5 \pm 2.0[2.0]^{\mathrm{a}}$ \\
\hline
\end{tabular}

${ }^{a}$ Median intake of fruits and vegetables.

Table 2. Reported home fruit/vegetable availability versus fruit/vegetable intake in mothers responding to an annual survey $(n=1463)$.

\begin{tabular}{lc}
\hline & Intake (servings/day) \\
\hline Fruit Availability & $2.8 \pm 1.5$ \\
Always & $2.2 \pm 1.5^{\mathrm{a}}$ \\
Almost always/usually & $1.4 \pm 1.4^{\mathrm{a}, \mathrm{b}}$ \\
Occasionally/rarely/never & \\
Vegetable Availability & $2.7 \pm 1.5$ \\
Always & $2.1 \pm 1.5^{\mathrm{a}}$ \\
Almost always/usually & $1.4 \pm 1.2^{\mathrm{a}, \mathrm{b}}$ \\
Occasionally/rarely/never
\end{tabular}

${ }^{a}$ Significantly different from "always" available $(P<0.001)$; ${ }^{\mathrm{b}}$ Significantly different from "almost always/usually" available $(P<0.001)$. but this difference was not significantly different, likely due to the small number of women reporting low availability $(\mathrm{n}=74)$. After adjusting for education, physical activity, marital status, and ethnicity, the relationship between BMI and vegetables "almost always/usually available" was attenuated and no longer statistically significant $(P=0.100)$ (Table 3).

\subsection{Associations between Child's Body Shape, FV Availability, and Mother's FV Intake}

Child's body shape was assessed using the images in Figure 1. Most women $(\mathrm{n}=915,77.7 \%)$ selected that their child resembled images $\mathrm{A}, \mathrm{B}$, or $\mathrm{C}$ (relating to $\leq 25$ th BMI percentile) while very few women ( $\mathrm{n}=70$, $5.9 \%$ ) selected images $\mathrm{F} / \mathrm{G}$ (relating to $\geq 90$ th $\mathrm{BMI}$ percentile). There was a significant association between mother's BMI and child's body shape $(P=0.001)$ (Figure 2). Additionally, those women who selected that her child resembled endomorphic images (E or F/G) had significantly higher BMIs than those who selected that their child resembled more ectomorphic or mesomorphic images $(\mathrm{A} / \mathrm{B} / \mathrm{C})$.

No significant differences existed amongst categories of child's body shape when compared to FV availability categories (data not shown). However, mothers who reported greater fruit intake were more likely to report their child's body shape in the lower BMI categories $(P=$ 0.007), though this inverse association did not hold true in relation to mother's vegetable intake and child's body shape $(P=0.809)$ (Table 4).

\section{Discussion}

This study provides hypothesis-generating results regarding the role of mothers' practices specific to FV intake/ availability and both her and her child's body size. There was a significant inverse relationship between mother's BMI and fruit and, to a lesser extent, vegetable availability, though we did not find a significant association between mother's BMI and reported FV intake. We also found an association between mother's fruit, but not vegetable, intake and the reported body shape of her child; mothers who reported children in the higher percentiles of BMI reported significantly lower fruit intake than mothers who reported their child's body size in the lower or normal BMI percentiles.

Short-term interventions indicate that increasing FV intake may be a good strategy for weight control as part of a balanced diet, as FV's increase feelings of satiety and may reduce intake of high-energy foods $[9,18]$. However, observational data evaluating the relationship between FV intake and BMI provide inconclusive results $[9,18,19]$. A systematic review of the literature suggests 
Table 3. Differences in BMI based on fruit/vegetable availability in mothers responding to an annual survey regarding fruits/vegetable in health $(n=1463)$.

\begin{tabular}{|c|c|c|c|c|c|c|}
\hline & \multirow{2}{*}{$\mathrm{n}(\%)$} & \multirow{2}{*}{$\operatorname{BMI}\left(\mathrm{kg} / \mathrm{m}^{2}\right)$} & \multicolumn{2}{|l|}{ Unadjusted } & \multicolumn{2}{|l|}{ Adjusted } \\
\hline & & & $\beta$ Coefficient $(95 \% \mathrm{CI})$ & $P$ value & $\beta$ Coefficient $(95 \% \mathrm{CI})$ & $P$ value \\
\hline \multicolumn{7}{|l|}{ Fruit Availability } \\
\hline Always & $734(50.0)$ & $26.6 \pm 6.6$ & Reference & & Reference & \\
\hline Almost always/usually & $629(42.8)$ & $28.1 \pm 7.9$ & $1.56(0.80-2.33)$ & $<0.001$ & $1.053(0.28-1.83)^{\mathrm{a}}$ & $0.008^{\mathrm{a}}$ \\
\hline Occasionally/rarely/ never & $106(7.2)$ & $29.4 \pm 7.1$ & $2.77(1.30-4.24)$ & $<0.001$ & $1.912(0.44-3.38)^{\mathrm{a}}$ & $0.011^{\mathrm{a}}$ \\
\hline \multicolumn{7}{|l|}{ Vegetable Availability } \\
\hline Always & $753(51.3)$ & $26.9 \pm 6.8$ & Reference & & Reference & \\
\hline Almost always/usually & $642(43.7)$ & $28.1 \pm 7.8$ & $1.25(0.49-2.01)$ & 0.001 & $0.628(-0.12-1.38)^{\mathrm{b}}$ & $0.100^{\mathrm{b}}$ \\
\hline Occasionally/rarely/never & $74(5.0)$ & $27.9 \pm 7.1$ & $1.06(-0.66-2.79)$ & 0.229 & $0.068(-1.62-1.76)^{\mathrm{b}}$ & $0.937^{\mathrm{b}}$ \\
\hline
\end{tabular}

${ }^{\mathrm{a}}$ Adjusted for education and physical activity; ${ }^{\mathrm{b}}$ Adjusted for education, physical activity, marital status, and ethnicity.

Table 4. Mother's fruit/vegetable intake versus mother's report of child's body shape in mothers responding to an annual survey regarding the role of fruits/vegetables in health.

\begin{tabular}{cccc}
\hline $\begin{array}{c}\text { Child's body } \\
\text { shape category }\end{array}$ & $\begin{array}{c}\text { Fruit or } \\
\text { vegetable }\end{array}$ & $\mathrm{n}(\%)$ & $\begin{array}{c}\text { Mother's intake } \\
(\text { mean } \pm \text { SD) }\end{array}$ \\
\hline $\mathrm{A} / \mathrm{B} / \mathrm{C}$ & Fruit & $910(77.8)$ & $2.5 \pm 1.6$ \\
$\mathrm{D}$ & Fruit & $123(10.5)$ & $2.5 \pm 1.4$ \\
$\mathrm{E}$ & Fruit & $68(5.8)$ & $2.3 \pm 1.3$ \\
$\mathrm{~F} / \mathrm{G}$ & Fruit & $68(5.8)$ & $2.0 \pm 1.6$ \\
$\mathrm{Total}$ & Fruit & $1169(100)$ & ${ }^{\mathrm{a}} 0.007$ \\
$\mathrm{~A} / \mathrm{B} / \mathrm{C}$ & Vegetable & $912(77.7)$ & $2.4 \pm 1.6$ \\
$\mathrm{D}$ & Vegetable & $123(10.5)$ & $2.5 \pm 1.5$ \\
$\mathrm{E}$ & Vegetable & $69(5.9)$ & $2.6 \pm 1.7$ \\
$\mathrm{~F} / \mathrm{G}$ & Vegetable & $69(5.9)$ & $2.1 \pm 1.3$ \\
Total & Vegetable & $1173(100)$ & ${ }^{\mathrm{a}} 0.809$ \\
\hline
\end{tabular}

${ }^{\mathrm{a} P}$ for trend across body shape categories.

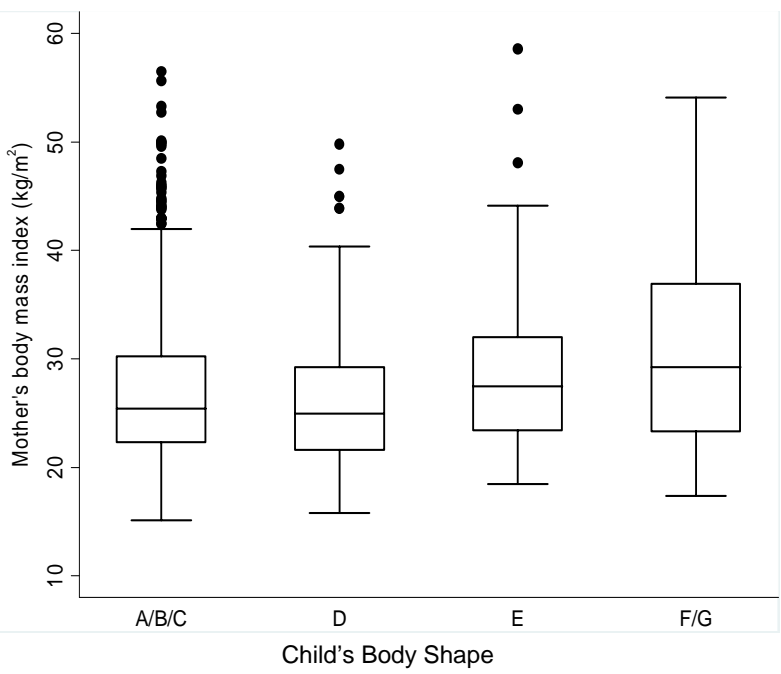

Figure 2. Comparison of BMI of mother's who selected images that most closely resembled their child's body shape. BMI values represent mean \pm SD. *Significantly different from the BMI of mothers who selected images $A / B / C$. $P$ trend $=0.001$. that there may be a relationship between low FV intake and higher BMI [19]; however, most studies that assess this relationship are designed with endpoints of FV intake and chronic disease outcomes [20], making it difficult to accurately extrapolate their findings to obesity, specifically. Our study did show a statistically significant relationship between fruit availability and BMI in mothers. These findings are consistent with much of the research regarding home FV availability and weight status, most of which has focused on children and adolescents and not adults $[21,22]$. Interestingly, this effect was not seen with vegetable availability and BMI, as mothers who selected that vegetables were "occasionally/rarely/ never available" in their home had lower BMIs than those who selected that vegetables were "almost always/ usually available." Supporting our data, an analysis from the USDA's 1994- 1996 Continuing Survey of Food Intakes by Individuals (CSFII) found that lower BMI was associated with greater fruit, but not vegetable, intake in adults and children [23]. Although we did not see a significant difference in BMI between women selecting the highest and lowest vegetable availability categories, it should be noted that women who indicated that vegetables were always available in their home had a lower BMI than those who did not choose this option. In addition, the BMI of this group was similar to the BMI of the group who indicated that fruits were always available in the home. One important issue that may potentially explain these results is the very low number of women who selected the lowest categories of vegetable availability (n $=74$ ) compared with those who indicated that vegetables were always available $(n=753)$. Furthermore, we did not obtain information regarding fruit and vegetable preparation methods. Vegetables consumed may have been fried or eaten with high calorie sauces or butter. This effect may explain the lack of an association between vegetable availability and BMI.

According to the social ecological theory, there are many factors that influence children's weight status, in- 
cluding parental behaviors and beliefs [12,15]. Our study explored the relationship between mother's BMI and child's (aged 2 - 12 years) body shape. Child's body shape was used as a proxy for child's BMI, as validated by Saxton et al. [24]. We found a significant association between mother's BMI and child's body shape. Women who selected that their child resembled an image of a larger body size had higher BMIs than those who selected a smaller body size. These findings agree with previous reports regarding parental BMI and child's weight status $[25,26]$.

In addition to the relationship between mother's BMI and child's body shape, we explored additional variables that may influence child's weight status. Previous work suggests that $\mathrm{FV}$ availability in the home is related to children's FV intake [22]. Children's FV intake may then confer benefits such as healthier weight status and reduced adiposity $[18,22]$. Despite this rationale, we failed to observe a relationship between FV availability and child's body shape. However, actual intake of FV in children was not assessed.

There is a large body of evidence exploring the relationship between mother-child FV intake resemblance $[13,14,27]$ as well as FV intake and BMI in both adults and children $[18,19]$. To our knowledge, this is the first study examining the relationship between maternal FV intake and child's body shape. We observed a significant inverse association between mother's fruit intake and child's body shape, suggesting that lower maternal fruit intake may be associated with her child's larger body size. This relationship did not exist between vegetable intake and child's shape, perhaps for the same reasons that it did not exist between mother's BMI and home vegetable availability. These findings provide further evidence suggesting that interventions to improve FV intake in children should also focus on promoting FV intake in mothers, as the family environment is a strong determinant of behavior development [12].

This is the first internet-based study to target a specific generation of mothers and for which we have novel information regarding mother's perception of child's body size to evaluate the role of FV in family health. The study was large with responses from over 1400 mothers. However, the study does have limitations. This study was conducted using cross-sectional data, limiting the ability to determine causation. Additionally, this study was conducted online and is therefore biased towards women with internet access. This study was also based on selfreported height and weight, FV intake, and FV availability; thus, respondents may have provided inaccurate information. Without a marker of validation (height and weight measured by a trained professional, a biomarker of intake such as serum carotenoids, or in-home appraisal of FV availability), we cannot ascertain the validity of self-reported data in the current study. We also did not have any information regarding other aspects of the diet, making it difficult to control for other potential confounders. Furthermore, social desirability may have resulted in answers that were not truly representative of actual behaviors and beliefs.

Additionally, our survey collected information on mother's perceptions of her child's body shape. Although these images were designed using BMI percentiles developed over 30 years ago, the scale itself was not developed until 2002 [17] and currently represents the most up-to-date scale of children's body images. Furthermore, this scale is unique as each image is an actual photograph of a child that correlates to a specific BMI, whereas previously developed scales simply depict silhouettes that do not necessarily correspond to actual BMI values [17]. A validation study by Saxton et al. in 2009 indicated that children were able to identify their body shape using these images with reasonably high accuracy [24]. However, there is literature that indicates that mothers tend to underestimate their child's body size [28,29]. Currently, $16.9 \%$ of American children are classified as obese [30], while only $5.9 \%$ of women in this survey chose the body images that most closely correlate with obesity $(\mathrm{F}=90$ th percentile; $G=97$ th percentile). This suggests that some women may have misclassified her child or that the sample of women surveyed is not largely representative of the American population.

\section{Conclusion}

The relationships between mother's BMI, FV intake, FV availability, and child's weight status are extremely complex and not well understood. Using a national sampling of mothers, we were able to evaluate FV availability in the home in relation to the BMI of the mother and also the body size of the child. The current study supports a role of fruit and, to a lesser degree, vegetable availability in BMI of mothers. Our data suggest a relationship between mother's fruit, but not vegetable, intake and child's body shape. The evidence generated from this study, particularly that regarding women's BMI and home FV availability, and mother's FV intake and child's body shape, should be further explored in longitudinal studies in order to inform on future interventions targeting FV consumption and healthy weight in the family setting.

\section{Acknowledgements}

The authors would like to acknowledge OnResearch Inc. for their efforts in survey design as well as the United States Department of Agriculture's National Need Fellowship that provided the necessary training for comple- 
tion of this research.

\section{REFERENCES}

[1] D. S. Freedman, "Obesity-United States, 1988-2008," MMWR Surveill Summ, Vol. 60, 2011, pp. 73-77.

[2] D. S. Ward, A. E. Vaughn, K. I. Bangdiwala, M. Campbell, D. J. Jones, A. T. Panter and J. Stevens, "Integrating a Family-Focused Approach into Child Obesity Prevention: Rationale and Design for the My Parenting Sos Study Randomized Control Trial," BMC Public Health, Vol. 11, No. 1, 2011, p. 431.

[3] P. M. Anderson and K. E. Butcher, "Childhood Obesity: Trends and Potential Causes," Future Child, Vol. 16, No. 1, 2006, pp. 19-45. doi:10.1353/foc.2006.0001

[4] A. H. Mokdad, B. A. Bowman, E. S. Ford, F. Vinicor, J. S. Marks and J. P. Koplan, "The Continuing Epidemics of Obesity and Diabetes in the United States," JAMA, Vol. 286, No. 10, 2001, pp. 1195-200.

[5] F. Bianchini, R. Kaaks and H. Vainio, "Overweight, Obesity, and Cancer Risk," The Lancet Oncology, Vol. 3, No. 9, 2002, pp. 565-74. doi:10.1016/S1470-2045(02)00849-5

[6] M. Bryant, J. Stevens, L. Wang, R. Tabak, J. Borja and M. E. Bentley, "Relationship between Home Fruit and Vegetable Availability and Infant and Maternal Dietary Intake in African-American Families: Evidence from the Exhaustive Home Food Inventory," Journal of the American Dietetic Association, Vol. 111, No. 10, 2011, pp. 14911497. doi:10.1016/j.jada.2011.07.007

[7] L. Hall, C. E. Collins, P. J. Morgan, T. L. Burrows, D. R. Lubans and R. Callister, "Children's Intake of Fruit and Selected Energy-Dense Nutrient-Poor Foods Is Associated with Fathers' Intake," Journal of the American Dietetic Association, Vol. 111, No. 7, 2011, pp. 1039-1044. doi:10.1016/j.jada.2011.04.008

[8] Healthy People 2020, "Healthy People 2020: Nutrition and Weight Status," 2010.

http://www.healthypeople.gov/2020/topicsobjectives 2020 /overview.aspx?topicid $=29$

[9] B. J. Rolls, J. A. Ello-Martin and B. C. Tohill, "What Can Intervention Studies Tell Us about the Relationship between Fruit and Vegetable Consumption and Weight Management?" Nutrition Reviews, Vol. 62, No. 1, 2004, pp. 1-17. doi:10.1111/j.1753-4887.2004.tb00001.x

[10] K. He, F. B. Hu, G. A. Colditz, J. E. Manson, W. C. Willett and S. Liu, "Changes in Intake of Fruits and Vegetables in Relation to Risk of Obesity and Weight Gain among Middle-Aged Women," International Journal of Obesity and Related Metabolic Disorders, Vol. 28, No. 12, 2004, pp. 1569-1574. doi:10.1038/sj.ijo.0802795

[11] S. Alinia, O. Hels and I. Tetens, "The Potential Association between Fruit Intake and Body Weight-A Review," Obesity Reviews, Vol. 10, No. 6, 2009, pp. 639-647. doi:10.1111/j.1467-789X.2009.00582.x

[12] N. Pearson, S. J. Biddle and T. Gorely, "Family Correlates of Fruit and Vegetable Consumption in Children and Adolescents: A Systematic Review," Public Health $\mathrm{Nu}$ - trition, Vol. 12, No. 2, 2009, pp. 267-283. doi:10.1017/S1368980008002589

[13] M. A. Beydoun and Y. Wang, "Parent-Child Dietary Intake Resemblance in the United States: Evidence from a Large Representative Survey," Social Science \& Medicine, Vol. 68, No. 12, 2009, pp. 2137-2144. doi:10.1016/j.socscimed.2009.03.029

[14] Y. Wang, M. A. Beydoun, J. Li, Y. Liu and L. A. Moreno, "Do Children and Their Parents Eat a Similar Diet? Resemblance in Child and Parental Dietary Intake: Systematic Review and Meta-Analysis," Journal of Epidemiology \& Community Health, Vol. 65, No. 2, 2011, pp. 177 189. doi:10.1136/jech.2009.095901

[15] S. Scaglioni, M. Salvioni and C. Galimberti, "Influence of Parental Attitudes in the Development of Children Eating Behaviour," British Journal of Nutrition, Vol. 99, No. 1, 2008, pp. S22-S25.

[16] M. Rasmussen, R. Krolner, K. I. Klepp, L. Lytle, J. Brug, E. Bere and P. Due, "Determinants of Fruit and Vegetable Consumption among Children and Adolescents: A Review of the Literature. Part I: Quantitative Studies," International Journal of Behavioral Nutrition and Physical Activity, Vol. 3, 2006, p. 22.

[17] H. Truby and S. J. Paxton, "Development of the Children's Body Image Scale," British Journal of Clinical Psychology, Vol. 41, No. 2, 2002, pp. 185-203.

[18] B. C. Tohill, J. Seymour, M. Serdula, L. Kettel-Khan and B. J. Rolls, "What Epidemiologic Studies Tell Us about the Relationship between Fruit and Vegetable Consumption and Body Weight," Nutrition Reviews, Vol. 62, No. 10, 2004, pp. $365-374$. doi:10.1111/j.1753-4887.2004.tb00007.x

[19] T. A. Ledoux, M. D. Hingle and T. Baranowski, "Relationship of Fruit and Vegetable Intake with Adiposity: A Systematic Review," Obesity Reviews, Vol. 12, No. 5, 2011, pp. e143-e150. doi:10.1111/j.1467-789X.2010.00786.X

[20] J. Pomerleau, K. Lock, C. Knai and M. McKee, "Interventions Designed to Increase Adult Fruit and Vegetable Intake Can Be Effective: A Systematic Review of the Literature," Journal of Nutrition, Vol. 135, No. 10, 2005 , pp. 2486-2495.

[21] K. W. Bauer, D. Neumark-Sztainer, J. A. Fulkerson, P. J. Hannan and M. Story, "Familial Correlates of Adolescent Girls' Physical Activity, Television Use, Dietary Intake, Weight, and Body Composition," International Journal of Behavioral Nutrition and Physical Activity, Vol. 8, No. 1, 2011, p. 25

[22] R. Jago, T. Baranowski and J. C. Baranowski, "Fruit and Vegetable Availability: A Micro Environmental Mediating Variable?" Public Health Nutrition, Vol. 10, No. 7, 2007, pp. 681-689. doi:10.1017/S1368980007441441

[23] B. H. Lin, "Higher Fruit Consumption Linked with Lower Body Mass Index," Food Reviews, Vol. 25, No. 3, 2002, pp. 28-32.

[24] J. Saxton, C. Hill, P. Chadwick and J. Wardle, "Weight Status and Perceived Body Size in Children," Archives of 
Disease in Childhood, Vol. 94, No. 12, 2009, pp. 944-949. doi:10.1136/adc.2009.162578

[25] C. Maffeis, G. Talamini and L. Tato, "Influence of Diet, Physical Activity and Parents' Obesity on Children's Adiposity: A Four-Year Longitudinal Study," International Journal of Obesity and Related Metabolic Disorders, Vol. 22, No. 8, 1998, pp. 758-764. doi:10.1038/sj.ijo.0800655

[26] C. Power, T. Pouliou, L. Li, R. Cooper and E. Hypponen, "Parental and Offspring Adiposity Associations: Insights from the 1958 British Birth Cohort," Annals of Human Biology, Vol. 38, No. 4, 2011, pp. 390-399. doi:10.3109/03014460.2011.591827

[27] E. L. Gibson, J. Wardle and C. J. Watts, "Fruit and Vegetable Consumption, Nutritional Knowledge and Beliefs in Mothers and Children," Appetite, Vol. 31, No. 2, 1998, pp.
205-228. doi:10.1006/appe.1998.0180

[28] Y. Manios, K. Kondaki, G. Kourlaba, E. Vasilopoulou and E. Grammatikaki, "Maternal Perceptions of Their Child's Weight Status: The Genesis Study," Public Health Nutrition, Vol. 12, No. 8, 2009, pp. 1099-1105. doi:10.1017/S1368980008004412

[29] M. L. de Hoog, K. Stronks, M. van Eijsden, R. J. Gemke and T. G. Vrijkotte, "Ethnic Differences in Maternal Underestimation of Offspring's Weight: The Abcd Study," International Journal of Obesity, Vol. 36, No. 1, 2011, pp. 53-60.

[30] C. L. Ogden, M. D. Carroll, B. K. Kit and K. M. Flegal, "Prevalence of Obesity and Trends in Body Mass Index among Us Children and Adolescents, 1999-2010," JAMA, Vol. 307, No. 5, 2012, pp. 483-490. doi:10.1001/jama.2012.40 